\title{
Desafio: Educação financeira ou sobrevivência
}

\author{
Challenge: Financial education or survival
}

Reto: Educación financiera o supervivencia

Recebido: 28/01/2022 | Revisado: 04/02/2022 |Aceito: 10/02/2022 | Publicado: 16/02/2022

Francisco César de Sousa

ORCID: https://orcid.org/0000-0001-9864-491X Instituto Federal de Educação, Ciência e Tecnologia do Tocantins, Brasil E-mail: Francisco.sousa10@estudante.ifto.edu.br

Weimar Silva Castilho

ORCID: https://orcid.org/0000-0002-6568-7910 Instituto Federal de Educação, Ciência e Tecnologia do Tocantins, Brasil E-mail: weimar@ifto.edu.br

Mary Lúcia Gomes Silveira de Senna

ORCID: https://orcid.org/0000-0002-4112-5470 Instituto Federal de Educação, Ciência e Tecnologia do Tocantins, Brasil marysenna@ifto.edu.br

Rivadavia Porto Cavalcante

ORCID: https://orcid.org/0000-0002-6568-7910 Instituto Federal de Educação, Ciência e Tecnologia do Tocantins, Brasil riva@ifto.edu.br

Rodrigo Carvalho Dias

ORCID: https://orcid.org/0000-0003-4615-653X Instituto Federal de Educação, Ciência e Tecnologia do Tocantins, Brasil rodrigo.dias@ifto.edu.br

\section{Resumo}

No trabalho foi desenvolvido uma pesquisa sobre a influência da Educação Financeira na vida dos estudantes do Ensino Médio profissionalizante. O objetivo dividiu-se em duas etapas: a primeira foi verificar o que leva pessoas com condições financeiras semelhantes, uns viverem endividados e outros não. O segundo foi verificar como outras pessoas podem se beneficiar da Educação Financeira, mesmo com baixa renda. A pesquisa com os participantes foi de natureza quali-quantitativa, realizada na sala de aula, na forma remota, na turma da $3^{\text {a }}$ Série do Curso técnico em Agropecuária Integrado ao Ensino Médio, no Instituto Federal de Educação, Ciência e Tecnologia do Tocantins IFTO, Campus Araguatins. Utilizando conteúdos de Matemática Financeira: Porcentagem, Juros Simples e Composto, e Introdução ao orçamento familiar, como meios e ferramentas de controle. Os resultados obtidos apresentaram a importância da Educação Financeira na disciplina de Matemática Financeira. Constatando-se que a Educação Financeira leva o indivíduo a mudanças de atitude, transformando também a vida financeira e familiar. Assim, pode-se perceber que o educar-se financeiramente pode evitar o endividamento, da mesma forma que o contrário, leva o indivíduo ao descontrole financeiro, e posteriormente, ao endividamento.

Palavras-chave: Matemática financeira; Educação financeira; Educação profissional.

\begin{abstract}
In the work, a research was carried out on the influence of Financial Education in the lives of high school students. The objective was divided into two stages: the first was to verify what makes people with similar financial conditions, some to live in goods and others not. The second is to verify how other people can be beneficiaries of Financial Education, even with low income. The research with the participants was of a qualitative-quantitative nature, carried out in the classroom, in a remote way, in the class of the 3rd Grade of the Technical Course in Agriculture and Livestock Integrated to High School, at the Federal Institute of Education, Science and Technology of Tocantins - IFTO, Campus Araguatins. Use of Financial Mathematics content: Percentage, Simple and Compound Interest, and Introduction to the family budget, as means and tools of control. The results obtained showed an importance of Financial Education in the discipline of Financial Mathematics. It appears that the Financial Education of the Individual and the Change of Attitude, also lead to Financial and Family Education. Thus, it can be seen that financial education can avoid indebtedness, in the same way as the opposite, leads the individual to financial lack, and later, to indebtedness.
\end{abstract}

Keywords: Financial mathematics; Financial education; Professional education.

\section{Resumen}

En el trabajo se realizó una investigación sobre la influencia de la Educación Financiera en la vida de los estudiantes de secundaria. El objetivo se dividió en dos etapas: la primera fue verificar qué hace que personas con 
condiciones financieras similares, unas vivan endeudadas y otras no. El segundo fue verificar cómo otras personas pueden beneficiarse de la Educación Financiera, incluso con bajos ingresos. La investigación con los participantes fue de carácter cualitativo-cuantitativo, realizada en el aula, de manera remota, en la clase del $3^{\circ}$ Grado del Curso Técnico en Agricultura Integrado al Bachillerato, en el Instituto Federal de Educación, Ciencias. y Tecnología de Tocantins - IFTO, Campus Araguatins. Utilizar contenidos de Matemática Financiera: Porcentaje, Interés Simple y Compuesto, e Introducción al presupuesto familiar, como medios y herramientas de control. Los resultados obtenidos mostraron la importancia de la Educación Financiera en la disciplina de Matemática Financiera. Observando que la Educación Financiera lleva al individuo a cambios de actitud, transformando también la vida financiera y familiar. Así, se puede ver que educarse financieramente puede evitar el endeudamiento, del mismo modo que lo contrario, lleva al individuo al descontrol financiero, y posteriormente al endeudamiento.

Palabras clave: Matemática financiera; Educación financiera; Educación profesional.

\section{Introdução}

O presente estudo apresenta uma reflexão acerca do controle financeiro das pessoas que possuem poder aquisitivo, que se pode considerar razoável, com renda entre três a dez salários mínimos, comparando os com aqueles que sobrevivem com ajuda financeira de terceiros.

Para Peter e Palmeira (2013) citados por (Cristoferi et al., 2017, p.7), definem que "educação financeira é a capacidade de entender finanças e assuntos relacionados”. Para Teixeira:

A Educação Financeira não consiste somente em economizar, cortar gastos, poupar e acumular dinheiro, é muito mais que isso. É buscar uma melhor qualidade de vida tanto hoje quanto no futuro, proporcionando a segurança material necessária para obter uma garantia para eventuais imprevistos. (Teixeira, 2015, p. 13).

A matemática financeira está inteiramente ligada à Educação Financeira, auxiliando no desenvolvimento e controle financeiro, levando o indivíduo a conhecer mais sobre gestão financeira, receitas e despesas. O orçamento familiar é uma ferramenta de controle de receitas e despesas.

Assim, a matemática financeira pode ser definida como uma área da Matemática que é utilizada pelos homens e instituições para auxiliar nos diversos negócios do cotidiano. Outra definição:

A matemática financeira é a área da matemática que estuda a equivalência de capitais no tempo, ou seja, como se comporta o valor do dinheiro no decorrer do tempo. Sendo uma área da Matemática Aplicada, que estuda diversas operações ligadas ao dia a dia das pessoas. (Gouveia, 2021)

Sabe-se, portanto, que entender finanças e manusear recursos financeiros tem sido assunto de relevância nos dias atuais. Porém, pessoas que tem uma renda considerável, estão descontrolados financeiramente (endividados), enquanto outras, não tendo essa renda, vivem sob controle financeiro. No entanto, aparecem neste contexto um grupo de pessoas que não possuem renda. O que dizer sobre Educação Financeira para estes que não têm renda? Essa pesquisa tem como objetivo geral o que leva pessoas com condições financeiras semelhantes, uns viverem endividados e outros não; e verificar como outras pessoas podem se beneficiar da educação financeira, mesmo sem renda. Conforme o documento "Estudo Especial no 80/2020" do Banco Central do Brasil, que aponta a existência de endividamento em todas as faixas de renda. Leva-se em consideração que a população brasileira na faixa salarial de $3.300,00$ a $11.000,00^{1}$ é de cerca de $15 \%$ da população, enquanto $5 \%$ tem renda superior a R\$11.000,00 (Brasil, 2020, p. 3). Especificamente, o presente estudo buscou verificar se esses grupos podem mudar a situação financeira colocando em prática princípios da Educação Financeira e verificar o que levam as pessoas a ficarem sem renda.

${ }^{1}$ Valores foram atualizados com base no Salário Mínimo vigente em 2021. 
Conforme pesquisa realizada pela Confederação Nacional de Dirigentes Lojistas (CNDL) e Serviço de Proteção ao Crédito (SPC), em 2019, aponta que "cresceu o número de brasileiros que acompanham e analisam seus ganhos e gastos por meio de um orçamento, passando de 55\% em 2017 para 63\% ao final de 2018" (Agência Brasil, 2019). Mesmo assim, um número significativo, não o fazem, o que se observa, no entanto, é que também uma quantidade expressiva que vivem abaixo da linha de pobreza, atingindo cerca de 27 milhões de pessoas, equivalente a 12,8\% da população brasileira é o que aponta o levantamento feito pela Fundação Getúlio Vargas (FGV), que destaca, também, que muitas famílias tentam sobreviver com o valor de R \$ 246,00 (US\$ 43,95) por mês (CNN Brasil,2021). Justifica-se então a relevância desta pesquisa sobre esse tema, considerando, portanto, esses três segmentos propostos: pessoas com renda acima de três salários mínimos per capita e descontrolados financeiramente, pessoas com renda inferior a três salários mínimos e controlados financeiramente e, os que vivem abaixo da linha de pobreza.

Neste caso, pretende-se verificar a proporção de famílias que estão enquadradas no rol de famílias que podem tirar algum proveito na utilização das ferramentas e meios de controle financeiro proposto pela Educação Financeira, e, também, se existe, famílias que seu poder econômico não se enquadram neste rol, considerando o desenvolvimento econômico e financeiro de famílias dos estudantes do IFTO - Campus Araguatins. Participaram da pesquisa os alunos da Turma D, da $3^{\text {a }}$ Série do Curso Técnico em Agropecuária Integrado ao Ensino Médio.

\section{Referencial Teórico}

Com referência às teorias de aprendizagens aqui apresentadas, em conformidade com Gagné, (apud Moreira, 1999, p. 78) "a aprendizagem é uma mudança comportamental persistente". Corroborando com o que se refere a mudança de comportamento, Borges et. al (2020, p.92) citam: “a abordagem comportamentalista - cognitivista de Gagné (1916 - 2002) dá importância à influência que os fatores externos ao ambiente exercem sobre os indivíduos e a força que a experiência tem sobre a aprendizagem". E quando se refere ao ensino de matemática financeira o aprendizado deve levar o indivíduo, neste caso, o aluno, provocando nele uma mudança de atitude, pois, este deverá aplicar à sua vida financeira cotidiana, portanto, uma mudança atitudinal. A Educação Financeira é uma consequência do verdadeiro aprendizado da matemática financeira, que tem auxiliado muitas pessoas a resolverem seus problemas.

Mas contradizendo o exposto acima, Rogers et al. (2008) aponta diferentemente, refutando a mudança comportamental pelo seu nível de conhecimento em educação financeira, visto que "parece não existir mudança de comportamento dos indivíduos conforme seu nível de instrução financeira. O comportamento entre estudantes com maior grau de instrução financeira foi semelhante ao grupo de baixo nível de instrução financeira, evidenciando os limites ao aprendizado, como sustentam os teóricos das Finanças Comportamentais". (Rogers, et al., 2008, p. 13)

Monteiro (2021) apoiado nos escritos de Ciavatta (2005), indica que quando se refere à formação integrada, destaca o sentido de humanização, o que a autora aponta um mundo em guerras, e uma constante violência, por isso a crescente desvalorização da vida em detrimento do trabalho, e que em função disso, percebe-se, que uma grande parcela da população luta por sobrevivência.

Corroborando com os autores supracitados, Saviani (2011) aponta a oposição dos interesses da burguesia e proletários, enquanto a burguesia busca se opor, cada vez mais à objetividade do conhecimento, os proletários exigem essa objetividade. Para uma melhor compreensão, vamos dizer que a burguesia é o grande capital, e os proletários, a classe trabalhadora e explorada, que busca sua própria sobrevivência.

Nesta perspectiva de sobreviver, é que encontram muitas famílias que por vários motivos, dentre eles o desemprego, proveniente de vários fatores, como por exemplo a Pandemia no Novo Coronavírus (COVID-19), que como consequência vem 
a pobreza, o endividamento e a inadimplência. Conforme pesquisa realizada pela Fundação Getúlio Vargas, o número de pessoas que vivem abaixo da linha de pobreza triplicou, atingindo 12,8\% da população brasileira. (CNN/Brasil, 2021).

Esta pobreza é algo que faz parte da estrutura da sociedade brasileira, e neste sentido Freire (1987) aponta que o desejo incontrolável de posse, faz desenvolver no indivíduo a convicção de que é possível transformar o seu poder de compra, a seu próprio interesse. Nesta concepção materialista da existência, completa Freire:

O dinheiro é a medida de todas as coisas. E o lucro, seu objetivo principal. Por isto é que, os opressores, o que vale é ter mais e cada vez mais, à custa, inclusive, do ter menos ou do nada ter dos oprimidos. Ser, para eles, é ter e ter como classe que tem (Freire, 1987, p. 46).

Neste sentido, cabe ressaltar que os que 'têm menos ou nada têm', são a grande maioria da população que trabalha ou está desempregada, mas que constituem uma classe dos menos favorecidos, com renda irrisória ou até mesmo sem renda, que lutam pela sobrevivência.

Esses fatos que ocorrem em nosso país, são os motivos que levam muitas pessoas a continuar lutando pela sua própria sobrevivência, enquanto que, por outro lado, outros procuram mais uma forma para se apropriarem mais e mais, de meios de produção e das riquezas. Essas lutas, são na verdade, as mudanças comportamentais provocadas pelas aprendizagens descritas por Gagné.

Contextualizando com as mudanças comportamentais propostas por Gagné, Bruner afirma que "ensinar é, em síntese, um esforço para auxiliar ou moldar o desenvolvimento" (apud Moreira, 1999, p. 82), neste caso, deve ser planejado para alcançar os objetivos desejados.

No sentido de alcançar estes objetivos, proposto por Gagné, na Educação Financeira é necessário a realização de uma transição do ensino da matemática financeira para que aconteça esta efetivação. Por isso, uma "reflexão crítica acerca de situações que influenciam a vida financeira das pessoas" conforme apontado por Cunha (2017, p. 662).

Seguindo a linha de pensamento de Hofmann \& Moro (2012, p. 38) que apresenta a matemática como "um instrumento criado pela humanidade para descrever o mundo real e ajudar na solução de problemas da vida cotidiana". Assim, a educação matemática aparece nestes últimos anos como destaque em pesquisas científicas, juntamente com os estudos de Educação Financeira, visto que, os resultados gerados e alcançados pela sociedade, justifica o ensino de matemática em nosso cotidiano (Teixeira, 2015). Dada a importância da Educação Financeira, Vieira, et al. (2011) reforça que a "educação financeira pode beneficiar todas as pessoas, independente do nível de renda" destacando os jovens que estão adentrando no mercado de trabalho, e, pode ser também, uma ferramenta de planejamento e controle.

Para uma melhor compreensão, a Educação Financeira é regida por alguns princípios, como: não gastar mais do que pode pagar; poupar pelo menos uma pequena parte da renda; evitar compras com parcelamento de longo prazo; diversificar os tipos de investimentos; controlar as rendas e gastos (CEF, 2009).

Além desses princípios, a Educação Financeira vale-se de ferramentas de controle, como orçamento que auxilia nas tomadas de decisões. Orçamento esse, que indica o equilíbrio entre receitas e despesas, ou seja, ganhos e gastos.

A pesquisa aponta a educação financeira como uma área emergente sendo oriunda da matemática financeira que vem permitindo ao estudante usar seus conceitos, assim como, também, os cálculos na sua vida social e econômica, conforme Cunha (2017). Partindo desse pressuposto, observa-se que através da aprendizagem conceitual da matemática financeira e dos cálculos dela proveniente, colabora com o indivíduo nas tomadas de decisões, cujos efeitos afetam a vida financeira e social.

Retomando às mudanças comportamentais, apoiado nos ensinamentos de Gagné, Cunha aponta que os alunos despertam a consciência quanto à atitude de investir, afirmando que após uma sequência de questões, eles conscientizam-se que "é preciso usar somente o excedente para investir" (Cunha, 2017, p.672). Considerando esse pressuposto, vimos a 
importância da utilização do orçamento pessoal e familiar, para que antecipadamente, o indivíduo possa saber qual o excedente a investir.

O IBGE (Instituto Brasileiro de Geografia e Estatística) aponta que em 2020 em função do avanço da pandemia do coronavírus o número de desocupados no país é de 12,850 milhões, (Ortiz, 2021). O que leva estas pessoas a se preocuparem como sobreviver com pouco ou sem nenhum dinheiro.

Na reportagem de Elaine Ortiz, (2021) apontam quatro estratégias a seguir depois que perder o emprego: 1. Fazer um planejamento financeiro (escolher uma ferramenta para auxiliar nesse processo), 2. Buscar fontes de renda extra (procurar uma maneira de ganhar alguma coisa), 3. Pesquisar sobre medidas emergenciais (pesquisar sobre a existência de algum programa de apoio) e 4. Fazer empréstimos saudáveis (buscar um empréstimo com a menor taxa de juro possível, para custear necessidades inadiáveis).

Considera-se, portanto, a importância da Educação Financeira, mesmo nos momentos de crise, pois uma das primeiras recomendações para que possa superar é o controle financeiro. Considerando, essa importância, a Base Nacional Comum Curricular (BNCC), contempla como componente curricular visando a Educação Financeira dos alunos, com conhecimentos sobre taxas de juros, inflação, aplicações financeiras, dentre outros, que poderão ser discutidos entre si (Brasil, 2018). Em 2020, o Ministério da Educação tornou obrigatório o ensino de Educação financeira nas escolas, sendo incorporada como um tema a ser desenvolvido dentro da matemática.

Para isso, o Ministério da Educação lançou no dia 17 de agosto de 2021, juntamente com outros órgãos, o Programa Educação Financeira nas Escolas, esse Programa tem o objetivo de capacitar os professores com cursos de formação em educação financeira, com o intuito de levar o tema para as salas de aula. Dessa maneira, chegando ao seu objetivo, que são os estudantes e consequentemente a família. (Brasil, 2021).

A implementação da educação financeira nas escolas, através da BNCC, visa o desenvolvimento econômico, financeiro e social da população do país. O envolvimento dos estudantes se dará lentamente, pois a Educação financeira se dá de forma teórico-prático. Neste sentido, percebemos que o aprendizado prático está de certa forma ligada à situação socioeconômica do aluno.

A trajetória escolar do Brasil é absolutamente incompatível com um país que se encontra entre as 10 maiores economias do mundo, mas bastante compatível com o grau de desigualdade socioeconômica que persiste, em grande medida responsável pelos baixíssimos índices de produtividade e pela elevada concentração da renda (Castro, 2019, p.7).

As diferenças socioeconômicas influenciam bastante no desempenho dos estudantes Castro (2019) o que também se aplica aos conhecimentos sobre finanças, deduz-se, portanto, que os indivíduos com melhores condições socioeconômicas, podem ter mais conhecimentos sobre finanças; o que nos leva a uma hipótese de que as famílias que vivem com auxílios de terceiros, ou seja, sobrevivem em função das ajudas sociais, quer do Estado ou da sociedade civil, neste caso, eles não têm o que controlar.

Assim, a Educação Financeira surtirá muito efeito para aqueles, que são privilegiados, por poderem de alguma forma ter algo para gerenciar.

\section{Metodologia}

Para chegar aos objetivos deste artigo foi realizada uma pesquisa de campo de natureza quali-quantitativa. Quanto aos procedimentos de coleta de dados, a pesquisa é classificada como Pesquisa de Levantamento, que segundo Carvalho et al., (2019, p.40), "é o tipo de pesquisa que visa investigar algo que se pretende conhecer de uma determinada população". 
Levantamento esse, no sentido de descobrir qual grau de contribuição tem a Educação Financeira nas famílias dos alunos do Instituto Federal do Tocantins - Campus Araguatins. Para isso, a pesquisa foi realizada na turma do $3^{\text {a }}$ Série " $D$ " - Técnico em Agropecuário Integrado ao Médio. O contato com os estudantes foi realizado em sala de aula no Google Meet $^{2}{ }^{2}$, quando no momento das aulas de matemática financeira ministradas no mês de outubro de 2021. Os conteúdos ministrados foram: porcentagem, juros simples, juros compostos, classificação de despesa e orçamento pessoal, com ênfase na Educação Financeira. Para obter os dados necessários utilizou-se da técnica de interrogação, que para Gil (2002) essa técnica de interrogação pode ser: "o questionário, a entrevista e o formulário". A coleta de dados seguiu os passos minuciosos para obtenção das informações mais precisas, segundos os preceitos de Lakatos (2003). Para realização do estudo, faz se necessário uma investigação preliminar. "A investigação preliminar - estudos exploratórios - deve ser realizada através de dois aspectos: documentos e contatos diretos" Lakatos (2003, p.159). Com base nestas informações, para a realização desta pesquisa foi utilizado um questionário com 5 (cinco) perguntas objetivas diretas múltipla escolha para os alunos da $3^{\text {a }}$ Série "D". Foi solicitado dados socioeconômicos dos alunos do Campus Araguatins, através de e-mail para a Gerência de Assistência ao Estudante do IFTO - Campus Araguatins. Com o objetivo de levantar as informações desejadas para este artigo.

\section{Resultados e Discussões}

Os resultados da pesquisa realizada na $3^{\mathrm{a}}$ série "D" do Curso Técnico em Agropecuária Integrado ao Ensino Médio, turma composta por 31 (trinta e um alunos), dos quais 16 (dezesseis) responderam ao questionário de pesquisa. Com base nos dados coletados constata-se que 51,61\% dos alunos da turma responderam à pesquisa.

Verificando as respostas para a 'pergunta 01 ', observa-se que a grande maioria das famílias não faz uso da matemática financeira nas tomadas de decisões financeiras, o que pode ser por falta de conhecimento ou desinformação, o que demonstra a Figura 1. Considerando que conhecimento e informação induz o indivíduo a mudanças de conceitos, e consequentemente, mudanças de atitudes.

Figura 1 - Pergunta do questionário.

Você por acaso faz uso prático da Matemática financeira, na tomada de decisões financeiras? 16 respostas

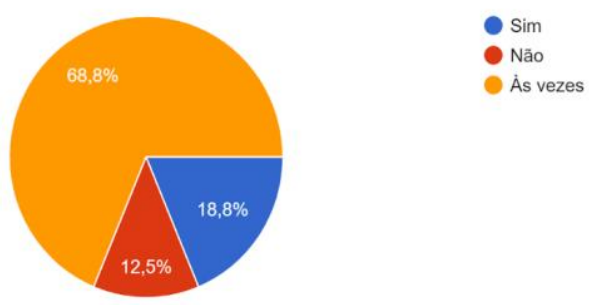

Fonte: Autores.

Mas depois dos esclarecimentos realizados nas aulas, dando ênfase à Educação Financeira, observa-se que apesar de não fazer uso da matemática financeira nas suas decisões financeiras, os alunos manifestaram que a Educação Financeira é muito importante para 31,3\% e importante para 62,2\%, no que diz respeito às finanças pessoal e familiar, conforme a Figura 2. O que podemos concluir que a aprendizagem leva o indivíduo a mudanças de atitude, conforme aponta Gagné (Apud Moreira, 1999).

\footnotetext{
${ }^{2}$ Link da aula de segunda-feira, dia 11/10. Para participar da videochamada, clique neste link: https://meet.google.com/jhn-jnhc-hmu
} 
Figura 2 - Pergunta do questionário.

Qual grau de contribuição trouxeram as aulas por mim ministradas para sua vida, ao se referir à Educação Financeira.

16 respostas

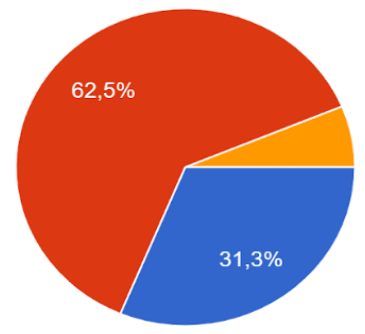

Nenhuma importância

Fonte: Autores.

Ao avaliar as respostas dadas, conclui-se que a Educação Financeira é um tema importante e que deve ser ministrado à sociedade de uma forma geral, conscientizando-os da sua importância. Relacionando a importância da Educação Financeira à situação que se encontra a sociedade, nesta busca incessante pelo dinheiro, conforme aponta Freire (1987), desejo incontrolável de posse e com o que Monteiro (2021) e Ciavatta (2005) acrescentam: violência constante e desvalorização da vida em detrimento do trabalho.

Para averiguar as condições socioeconômicas das famílias desses alunos foi perguntado: Você recebe algum tipo de bolsa? Para essa pergunta foram dadas as seguintes respostas: 62,5\% responderam não, demonstrando aparentemente que existe uma situação meio equilibrada, enquanto $37,5 \%$ sim, é o que indica a Figura 3.

Figura 3 - Pergunta do questionário.

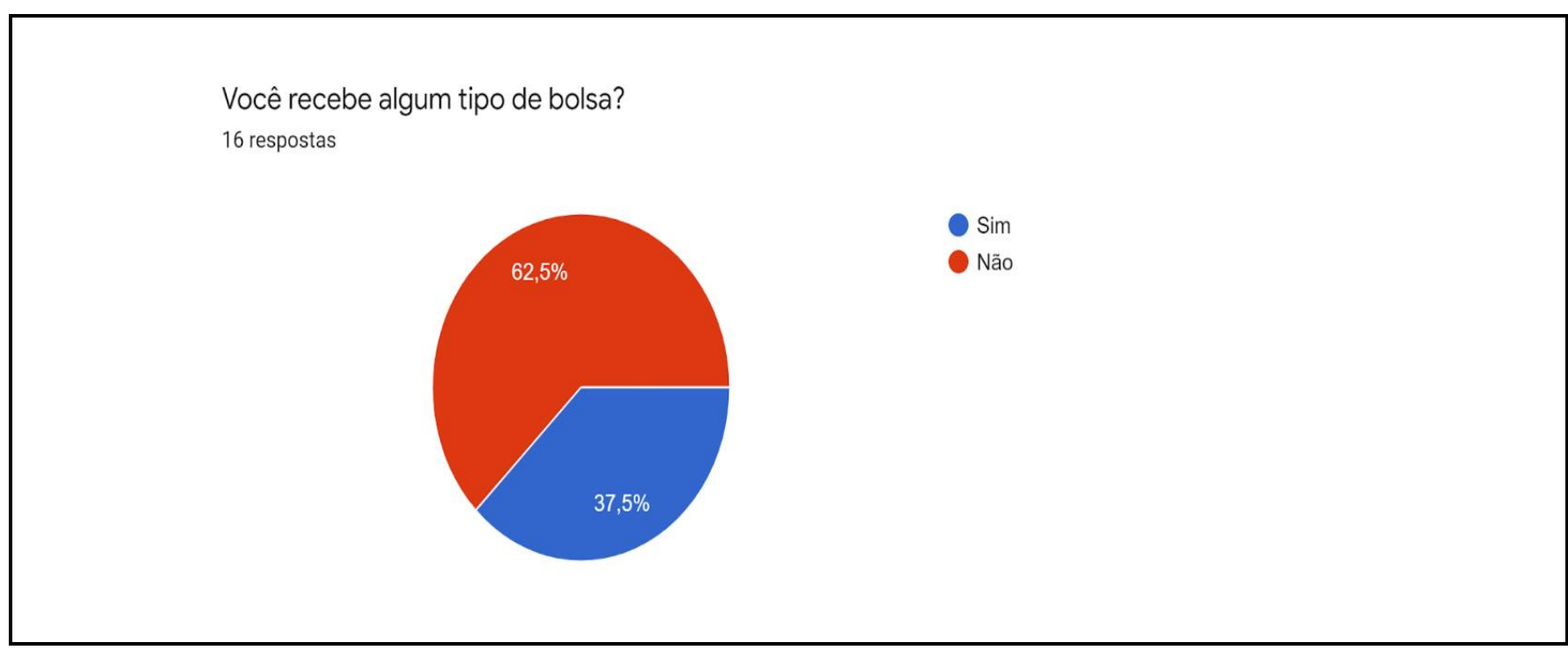

Fonte: Autores.

Após analisar essas respostas, nos leva a pensar que a maioria desses alunos pertencem a famílias bem estruturadas financeiramente, e que na verdade não necessitam de auxílios para manter-se nos estudos. Muito embora a realidade seja bem 
diferente. Quando confrontado com as informações trazidas pela pesquisa da fundação Getúlio Vargas, que mostra o aumento do número de pessoas que vivem abaixo da linha de pobreza (CNN/BRASIL, 2021).

Quando foi perguntado sobre os motivos de não receber as bolsas/auxílio, pergunta 04: Se não recebe, qual motivo? Das 11 (onze) respostas, 45,5\% responderam: Não necessitar, pois a família é bem estruturada, 27,3\% necessita, mas não se enquadrou no edital por falta de documentos comprobatórios e $27,3 \%$, necessita e ficou na lista de espera, é o que consta na figura 4.

Observa-se assim, que a constante luta pela sobrevivência é o motivo pelo qual muitos estudantes recorrem a auxílios e bolsas de estudo.

Figura 4 - Pergunta do questionário.

Se não recebe, qual motivo?

11 respostas

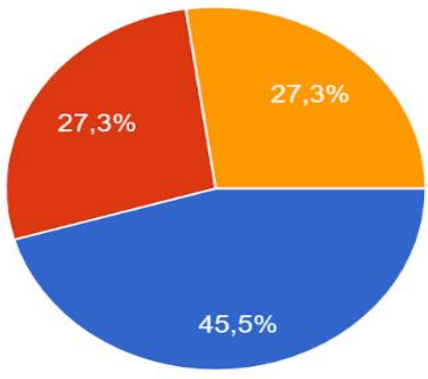

Não necessita, pois a família é bem estruturada.

Necessita, mas não se enquadrou no edital por falta de documentos comprobatório

Necessita, mas ficou na lista de espera.

Necessita, mas não preencheu os documentos solicitados em tempo hábil.

Fonte: Autores.

Analisando-os com cautela, percebe-se que 54,6\% dos que não recebem bolsas/auxílios, se enquadram juntamente com os $37,5 \%$ que recebem, totalizando $81,25 \%$, que vivem em condições de pobreza. Quando se relaciona com os dados socioeconômicos conforme a Tabela 1, abaixo, mostra que o somatório das famílias cuja renda é de: Até 0,5 salários mínimos somados com os que têm renda de mais de 0,5 a 1,0 salários mínimos, perfazem um total de $79 \%$. Que configura, se considerarmos uma margem de erro de $+/-3 \%$ para mais ou para menos, os dados confirmam o estado de necessidade de muitos alunos do Campus Araguatins.

Observa-se, portanto, que as condições socioeconômicas desses estudantes, com base nas respostas dadas no questionário, demonstram que a maioria vive sob condições precárias, o que confirma o relatório fornecido pela Gerência de Assistência ao Estudante. 
Tabela 1 - Dados socioeconômicos dos 1.319 alunos do Campus Araguatins.

\begin{tabular}{|l|c|c|c|}
\hline \multicolumn{1}{|c|}{ ITEM } & RENDA PER-CAPITA & QUANTIDADE DE ALUNOS & $\%$ \\
\hline 01 & Até 0,5 salários mínimos & 815 & 17 \\
\hline 02 & Mais de 0,5 a 1,0 & 225 & 6 \\
\hline 03 & Mais de 1,0 até 1,5 & 84 & 4 \\
\hline 04 & Mais de 1,5 até 2,5 & 53 & 1 \\
\hline 05 & Mais de 2,5 até 3,0 & 09 & 3 \\
\hline 06 & Mais de 3,0 & 36 & 7 \\
\hline 07 & Não informou renda & 97 & \\
\hline
\end{tabular}

Fonte: Sistema Acadêmico - Siga-Edu EPCT.

Analisando os dados da tabela 1, observa-se que apenas 3\% têm renda superior a 3 salários mínimos, $1 \%$ estão entre mais 2,5 a 3 salários mínimos, $4 \%$ tem renda entre mais de 1,5 e 2,5 salários mínimos e 6\% mais de 1 até 2,5 salários mínimos. Que leva a concluir que aproximadamente 15\% das famílias dos alunos do IFTO - Campus Araguatins, vivem com uma renda per-capita superior a 1 salário mínimo, destas aproximadamente $45 \%$ se enquadram com renda entre mais de 1 até 2,5 salários mínimos. Demonstrando assim, que menos de $10 \%$ se encontram em situação mais confortável.

Considerando que a grande maioria, não faz uso da matemática financeira nas tomadas de decisões, e consequentemente, também não utilizam o orçamento pessoal e familiar, como ferramenta que subsidia na Educação Financeira.

Ressalta-se, portanto, que neste caso, o motivo de viverem com essa renda, quer maior ou menor do que três salários mínimos, pode estar ligado à Educação Financeira, mas os demais, que sobrevivem com valores irrisórios que não chegam a um salário mínimo, a esses, é que não se sabe qual a verdadeira influência da Educação Financeira. Considerando que a Educação Financeira ajuda a gerir o patrimônio, através do controle dos gastos, evitando assim o endividamento.

De acordo com as informações trazidas pela reportagem de Elaine Ortiz, percebemos que, mesmo nos momentos difíceis da vida, a Educação Financeira, através de suas ferramentas de controle, aparece como alternativa para dirimir o problema. Mas considerando o pressuposto de que a situação socioeconômica do indivíduo influencia no aprendizado e na prática financeira, ou melhor, na Educação Financeira.

\section{Considerações Finais}

Diante do exposto no discorrer do artigo, encontramos pontos que nos chama a atenção, no que diz respeito ao conhecimento e prática da Educação Financeira, que por ser um assunto atual e relevante, que está sendo introduzido no currículo escolar, como tema integrante da matemática, através da BNCC, e que o mesmo está sendo implantado de forma obrigatória pelo Ministério da Educação.

Observa-se que grande parte das famílias dos estudantes do IFTO, Campus Araguatins, que embora seja uma pequena amostra, mas que reflete a realidade brasileira. O que podemos extrair é: A Educação Financeira pode ajudar muito, no sentido de gerenciar as receitas e controlar as despesas das famílias que têm uma renda maior que 01 (um) salário mínimo 
per capita, considerando que esse valor, embora seja pouco, mas que, se pode usar como referência, considerando que seja uma família de poucos membros. Conscientizando de como e quando efetuar os gastos, procurando sempre gastar menos do que ganha, para assim ter sempre uma reserva financeira.

Já às demais, cuja renda per capita, não chega a um salário mínimo, embora procure economizar, de diversas formas, dificilmente conseguirá sair do fosso, pois tudo que produz, pela força do seu trabalho, dará mal para seu consumo imediato, gastos exclusivos com as necessidades básicas para sobrevivência.

Assim, a própria aprendizagem sobre finanças, terminam sendo prejudicadas, considerando que as pessoas cuja as condições socioeconômicas são ruins, também ruim é o aprendizado e a prática sobre Educação Financeira.

Diante deste cenário de desafio: Educação Financeira ou sobrevivência? Conclui-se que Educação Financeira para as famílias que dela bem puder fazer uso, usufruindo de tudo que for possível. E aos sobreviventes, considerando que não foi possível identificar os reais motivos que levam a essa situação, proponho um estudo mais profundo, que possa identificar o que leva a esse grupo crescer mais e mais: que não seja a exploração financeira pelo grande capital.

Considerando a amplitude do tema educação financeira, bem como a sua complexidade, sugerimos um estudo que venha explicitar a realidade desse grupo de pessoas que até aqui, não foi possível encontrar uma relação com os benefícios, ora propagado da Educação Financeira: os sobreviventes da exploração do capitalismo.

\section{Referências}

Agência Brasil (2019). Pesquisa mostra que 63\% dos brasileiros analisam seus gastos e ganhos https://radiojornal.ne10.uol.com.br/noticia/2019/01/23/pesquisa-mostra-que-63porcento-dos-brasileiros-analisam-seus-gastos-e-ganhos-63688.

Borges, T. D. F. F.; Oliveira, G. S; Borges, J. R. A \& Saad, D. N. (2020). Teoria da Instrução de Gagné e o Ensino da Matemática, Cadernos da Fucamp, 19 (40), 90-111. https://www.fucamp.edu.br > article > download..

Brasil. (2018). Base Nacional Comum Curricular - BNCC-2018, http://basenacionalcomum.mec.gov.br/images/BNCC_EI_EF_110518_versaofinal_site.pdf .

Brasil, (2021).Programa de Educação Financeira nas Escolas, 2021. https://www.gov.br/mec/pt-br/assuntos/noticias/mec-lanca-programa-educacao-financeiranas-escolas.

Carvalho, L. O. R.; Duarte, F. R.; Menezes, A. H. N \& Souza, T. E. S. [et al.] Metodologia científica: teoria e aplicação na educação a distância - Petrolina PE, 2019.

Castro, M. H. G. de. Em busca de mais qualidade e equidade na educação básica- Revista Pátio Ensino Fundamental - No 88 : Em busca da escola de excelência. 6 a 9. https://desafiosdaeducacao.grupoa.com.br/qualidade-equidade-educacao-basica/.

CNN Brasil.(2021). População abaixo da linha da pobreza triplica e atinge 27 milhões de brasileiros. https://www.cnnbrasil.com.br/nacional/populacao-abaixoda-linha-da-pobreza-triplica-e-atinge-27-milhoes-de-brasileiros/

Cristoferi, F. R.; Rauber, A. D. \& Rauber, L. A.. (2017). Educação Financeira: A Introdução de Responsabilidades Futuras, 13 ENCITEC,. https://www2.fag.edu.br/coopex/inscricao/arquivos/encitec/20171024-090434_arquivo.pdf .

Cunha, C. L. da \& Laudares, J. B. (2017). Resolução de Problemas na Matemática financeira para Tratamento de Questões da Educação Financeira no Ensino Médio. Bolema, Rio Claro-SP, 31(58),. 659-678, DOI: http://dx.doi.org/10.1590/1980-4415v31n58a07

Freire, P.. (1987). Pedagogia do Oprimido, (17 ed.), Paz e Terra.

Gil, A. C.. (2002). Como elaborar projetos de pesquisa. (4. Ed.) Atlas.

Gouveia, R. Matemática Financeira. https://www.todamateria.com.br/matematica-financeira-conceitos-formulas/.

Hofmann, R. M. \& Moro, M. L. F.. (2012). Educação Matemática e educação financeira: perspectiva para a ENEF. Zetetike - FE/Unicamp. 20 (38) 37-54 DOI:10.20396/zet.v20i38.8646609

Lakatos, E. M. \& Marconi, M. A..(2003). Fundamentos de metodologia científica. (5 ed.) - São Paulo.

Moreira, M. A. (1942). Teorias de Aprendizagem: EPU, 1999.

Ortiz, E., (2021) Perdi o emprego, e agora? Como sobreviver em tempos de crise. https://www.creditas.com/exponencial/perdi-o-emprego-e-agora/.

Rogers, P; Securato, J. R.; \& Favorato, V. (2008). Efeito Educação financeira no processo de tomada de decisões em investimento: um estudo a luz das finanças comportamentais. https://www.researchgate.net/publication/281901689_Efeito_educacao_financeira_no_processo_de_tomada_de_ decisoes_em_investimentos_Um_estudo_a_luz_das_financas_comportamentais. 
Research, Society and Development, v. 11, n. 3, e13611326269, 2022

(CC BY 4.0) | ISSN 2525-3409 | DOI: http://dx.doi.org/10.33448/rsd-v11i3.26269

Saviani, D. (2011). Pedagogia histórico-crítica: primeiras aproximações. (11. Ed.rev) - Campinas, SP: Autores Associados, 2011.

Sistema Acadêmico - Siga-Edu EPCT-13.16-5 (2021). Dados socioeconômicos. https://sigaedu.ifto.edu.br/sigaept-edu-web-v1/pages/inicio.jsf.

Teixeira, J. (2015) Um estudo diagnóstico sobre a percepção da relação entre educação financeira e matemática financeira. 1Library https://1library.org/document/y4wn1w5q-diagnostico-percepcao-educacao-matematica-financeira-doutorado-educacao-matematica.html.

Vieira, S. F. A; Bataglia, R. T. M. \& Sereia, V. J.. Educação Financeira e decisões de consumo, investimento e poupança: uma análise dos alunos de uma universidade pública do Norte do Paraná. 2011. Revista de Administração da UNIMEP, 9 (3), 61-86. DOI:10.15600/1679-5350/rau.v9n3p61-86 